\title{
Preparing Returning Workplaces for COVID-19: An Occupational Health Perspective.
}

Mikhael Yosia, Nuri Purwito Adi

Department of Community Medicine, Faculty of Medicine Universitas Indonesia, Indonesia

\section{Corresponding Author:}

Mikhael Yosia

081378778784

mikhael.yosia@gmail.com

\begin{abstract}
With the COVID-19 pandemic continuing and the resulting economic burden increasingly apparent, the Indonesian government began to prepare a "new normal" phase and make peace with COVID-19. From this new decision arises the question of the readiness of businesses and the industrial sector to resume operations amid COVID-19. This article aims to provide concise and precise information about the preparations that can be made by businesses to operate safely amid COVID-19 based on existing scientific studies and literatures. From the literature visits it can be concluded that transmission and danger of a COVID-19 pandemic can be prevented through: creation of infectious disease prevention and response plan, implementing basic infection prevention measures, policies and procedures for proper identification and isolation of sick people, applying flexibilities in policies, and protections in the workplace.
\end{abstract}

Keywords: COVID-19; occupational health; returning to work 


\section{Introduction}

Coronavirus disease 2019 (COVID-19) is an infectious respiratory disease that is first identified in December 2019 in Wuhan, Hubei province, China. Since then the disease has spread globally, resulting in the coronavirus pandemic. ${ }^{1}$ As of May 2020, the world faced around 5 million positive cases and 328 thousand death due to COVID-19. ${ }^{2}$

With the pandemic continues to ravage countries around the world, large strains are being put on the economic sectors as industries come to a sudden halt. ${ }^{3}$ Several countries had decided to ease their lockdown policy and allow select businesses or industrial sectors to restart their operation. Unfortunately, the pandemic would still be there, and these returning workers are faced with looming risk of COVID-19 infections. ${ }^{4}$

To lessen the impact of COVID-19 outbreak on returning businesses, workers, customers, and the public, all employers need to plan their business operations around COVID-19. These may involve updating business continuity plans to address the specific exposure risks, sources of exposure, routes of transmission, and other unique characteristics of SARS-CoV-2. Lack of continuity planning would cause subsequent problems as employers would later struggle to combat challenges of COVID-19 with insufficient resources while workers might come under similar stress as they are not adequately trained for jobs they may have to perform under pandemic conditions. ${ }^{5}$

This guidance is made as a suggestion for planning purposes. Employers and workers should use this planning guidance to help identify risk levels in workplace settings and to determine any appropriate control measures that they deemed appropriate to implement. Additional guidance may be needed as COVID-19 pandemic will continuously change.

\section{How the outbreak could affect workplace}

As we continue to face the pandemic, it is clear that the extensive spread of COVID-19 had a significant impact on businesses. With vaccines still in development, it is more than likely that the pandemic may continue as an extended event. ${ }^{6}$ In lieu, workplaces should prepare to face absenteeism, change in demand, and interruption to their supply and delivery chain. ${ }^{7}$

Amidst the pandemic, employees might be absent from work because they are sick or because they have to take care of their sick family members. Employees might be missing work because they need to take care of their children since most schools and daycare centers are closed. Some might have to take prolonged leave from work as they have high-risk people at home and was afraid of spreading the disease. ${ }^{8}$

It is more than likely that costumer would have a shift in demand. Infection prevention-related items such as masks, gloves, and disinfectants had seen a high rise in demands while interest in other unnecessary items may decline. ${ }^{9}$ Consumer shopping patterns may also change as people start to emphasize reducing person-to-person contact. Consumers may start to shop at off-peak hours, choosing online shopping and home delivery options or drive-through services whenever available. ${ }^{10}$

Although businesses may return their operation, some countries would still impose travel restrictions and limited social distancing which may pose disruption in the supply and delivery chain. Shipment of raw materials and goods may be delayed or outright banned to and from certain areas. Possibilities of subsequent temporary stop in service, production and/or delivery is a real threat that every employer should consider amidst COVID-19. ${ }^{11}$ 


\section{Steps that can be taken by the employer to reduce the risk of exposure to SARS-CoV-2}

This section covers general steps that employers can take to prevent workers from SARS-CoV-2 that causes COVID-19.

Creation of infectious disease prevention and response plan.

Development of plans needed to curb the risk posed by COVID-19. These plans should consider national and local government guidance (travel restriction, social distancing, work shifts, downsizing of operations, etc.). These plans should also consider the level of risk for different work areas and tasks.

In developing the plan, the employer should be able to identify where and how sources of SARS-CoV2 might be exposed to their employees at work (from co-workers or customers with a high risk of infection or those who frequented high-risk areas). Consideration should also be made to risk factors outside of work; at home or in the community. Unique individual risk factors should also be taken into accounts, this includes but not limited to; age, pregnancy, and previous chronic diseases. After the identification of all these risks, the infectious disease prevention and response plan should sufficiently and realistically address these risks. ${ }^{12}$

\section{Implementing basic infection prevention measures}

In numerous businesses, employee protection will depend on basic infection prevention measures. This includes an emphasis on the implementation of good hygiene and common infection control practices.

- The employer must promote correct handwashing practices which include the provision of proper infrastructure and equipment for workers, visitors, and/or customers to wash their hands. ${ }^{13}$

- Provision of soap and running water are ideal, if not available, provide alcohol-based hand rubs with at least $60 \%$ alcohol. ${ }^{13}$

- Other supporting infection control infrastructure such as tissue paper and trash bin should be made readily available in the workplace.

- Workers must be made aware of their health conditions, employer must actively encourage and allow workers to stay home if they are sick. ${ }^{14}$

- Provide information on proper respiratory etiquette and encourage its application on a daily basis.

- The worker should avoid sharing equipment (phones, desk, work tools) when possible ${ }^{15}$

- To increase or support physical distancing policies, the employer should look at the possibility to continue working from home (WFH) practices, flexible worksite, and flexible work hours. ${ }^{16}$

- Regular housekeeping practices would include cleaning and disinfection of surfaces, work equipment, and work environment. ${ }^{17}$

\section{Policies and procedures for proper identification and isolation of sick people}

With the ongoing pandemic, there's a high risk that sick individuals may be present in work/business areas. Proper identification and temporary isolation of these individuals is important in protecting other people present at the worksite. Several steps can be taken by the employer in planning this process

- Provide information on signs and symptoms of COVID-19 and encourage employees to selfmonitor when they suspect possible exposure. ${ }^{14}$

- Creation of policies and procedures for workers who are sick or having symptoms related to COVID-19. ${ }^{14}$

- If possible, create policies for immediate isolation of those with COVID-19 signs and symptoms. When specific isolations rooms are not available, designated areas separated by closed doors can be used as a temporary isolation room until the suspected individual can be taken to healthcare facilities. ${ }^{18}$

- Limit workers' contact with isolation rooms/areas harboring suspected individuals.

- Provide and encourage the use of face masks for individuals suspected with COVID-19. 
- Workers with a high risk of contact/continuous contact with a sick person should be protected by proper personal protective equipment (PPE), additional engineering and administrative controls, and safe work practices. ${ }^{18}$

Applying flexibilities and protections in the workplace

Employees can sometimes feel obliged to stay at work or unfamiliar with new workplace flexibilities policies that are being developed for this pandemic. The employer should ensure that proper development, promotion, and implementation of workplace flexibilities and protection policies is being done in their workplace.

- Continuously encourage sick workers to stay at home.

- Create a flexible sick leaves policy that is in accordance with public health recommendations and local/national government policies.

- Take active steps to promote and ensure that workers are aware of the sick leaves policies.

- If possible, refrain from asking for a sick note from a healthcare provider as healthcare facilities may be overburdened and it poses an additional risk of infection to the workers. ${ }^{19}$

- Be aware that more workers might need to stay at home to take care of sick family members. When possible, create temporary flexible rules that would allow workers to stay home and take care of sick family members.

- Address employees' concerns on their salary, absence, health, and safety in the workplace. When possible, the employer should provide education and information on worker health and safety (which may include proper PPE and correct hygiene practice). Information can be an important point that encourages workers to stay at work.

- When appropriate, make sure that the workers are made aware of any health insurance or health benefits for COVID-19 medical care.

Applying workplace controls.

Another action that can be done by employers to remove workplace hazards to systematically remove these hazards from the workplace. During this COVID-19 pandemic, it may not be possible to eliminate the hazard but there are still several workplace controls measures that can be applied to effectively reduce the risk of infections. This includes engineering controls, administrative controls, and safe work practices, and PPE. Each type of control measure would have its own advantages and disadvantages. It should be noted that sometimes a combination of control measures can be necessary to protect workers from COVID-19. ${ }^{20}$

\section{Engineering control}

In engineering control, the employer would attempt to isolate its worker from SARS-CoV-2. In the appropriate workplace, engineering control may be an easy and economical solution to reduce the risk of COVID-19. This method might be one of the most effective as it doesn't rely on human behavior to alleviate the hazard. ${ }^{21}$ Some engineering control that can be applied may include:

- Purchasing and installing appropriate air filters.

- Increase ventilation and airflow in the workplace.

- Creation of appropriate physical barriers (such as plastic cover in cashier or faceguard for employees).

- Creation of infrastructure that could limit person-to-person interaction (drive-through services, intercom).

$\underline{\text { Administrative control and safe work practices }}$

Administrative control usually involves policy or standard of procedures that are meant to minimize risk or hazard at work. ${ }^{22}$ These would include, but not limited to:

- Creation of appropriate sick leave policies and encourage sick employees to stay at home.

- Encourage minimalization of person-to-person contact through virtual meetings and distance working whenever possible. 
- Encourage social distancing through the creation of a work shift that could reduce the number of workers present at the workplace at the same time.

- Rectify traveling policy and reduce unnecessary travel.

- Continuously address worker concern and spread useful information through appropriate media (forums, internet newsletter, etc).

- Provision of appropriate training and education material related to COVID-19.

Safe work practices are part of the administrative control that aims to reduce exposure to COVID-19. This would include:

- Provision of infrastructure (tissue, trash can, appropriate hand washing equipment) that encourages employees to keep their personal hygiene.

- Actively encourage and put in place policies for compulsory hand washing.

Personal protective equipment (PPE)

Proper usage of PPE to a certain extent may help control exposure to SARS-CoV-2. Employers should remember that usage of PPE relies on individual employees' habits and knowledge. With that being said, the employer is obliged to still provide appropriate PPE to their workers. ${ }^{23}$ PPE includes any equipment that can be used by an individual to minimize exposure from the hazard (mask, goggles, gloves, face shield, etc). The recommendation of which PPE to use might differ based on employees' risk and government policies. Consult with your national Ministry of Health, Ministry of Workforce, or occupational health physicians for appropriate PPE in your workplace. As a rough guideline, the PPE chosen should:

- Appropriately address the risk and hazard that is exposed to the workers.

- Of good quality and properly fit the workers.

- Properly worn.

- Checked regularly and replaced when appropriate.

- Proper removal, cleaning, storage, and disposal to avoid contaminations.

\section{Closing remarks}

Employers must not forget to consult local government resources and agencies when preparing their workplace for COVID-19. With the pandemic still ongoing and knowledge on the disease changes on a daily basis, it is recommended that employer should keep their policy flexible to address any appropriate changes. Whenever appropriate, consult with your occupational health physician to ensure that an appropriate policy had been made for your workplace. Through the creation of a comprehensive safety and health program, the employer may substantially reduce the risk of COVID-19 exposure in their workplace and prevent illness to their workers.

\section{Conflict of Interest}

Authors of this study declares no conflict of interest.

\section{Acknowledgement}

Department of Community Medicine, Faculty of Medicine Universitas Indonesia. 


\section{References}

${ }^{1}$ Liu Y, Gayle AA, Wilder-Smith A, Rocklöv J. The reproductive number of COVID-19 is higher compared to SARS coronavirus. Journal of travel medicine. 2020 Mar 13.

${ }^{2}$ World Health Organization. Coronavirus disease 2019 (COVID-19): situation report, 113.

${ }^{3}$ Ozili PK, Arun T. Spillover of COVID-19: impact on the Global Economy. Available at SSRN 3562570. 2020 Mar 27.

${ }^{4}$ Ichino A, Calzolari G, Mattozzi A, Rustichini A, Zanella G, Anelli M. Transition steps to stop COVID19 without killing the world economy. VoxEU. org. 2020 Mar;25.

${ }^{5}$ Fernandes N. Economic effects of coronavirus outbreak (COVID-19) on the world economy. Available at SSRN 3557504. 2020 Mar 22.

${ }^{6}$ Anderson RM, Heesterbeek H, Klinkenberg D, Hollingsworth TD. How will country-based mitigation measures influence the course of the COVID-19 epidemic?. The Lancet. 2020 Mar 21;395(10228):931-4.

${ }^{7}$ Hevia C, Neumeyer PA. A perfect storm: COVID-19 in emerging economies. VoxEU CEPR Policy Portal. Available at https://voxeu. org/article/perfect-stormcovid-19-emerging-economies. 2020 .

${ }^{8}$ D'Adamo H, Yoshikawa T, Ouslander JG. Coronavirus disease 2019 in geriatrics and long-term care: the ABCDs of COVID-19. Journal of the American Geriatrics Society. 2020 Mar 25.

${ }^{9}$ Guerrieri V, Lorenzoni G, Straub L, Werning I. Macroeconomic Implications of COVID-19: Can Negative Supply Shocks Cause Demand Shortages?. National Bureau of Economic Research; 2020 Apr 2.

${ }^{10}$ Richards TJ, Rickard B. COVID-19 impact on fruit and vegetable markets. Canadian Journal of Agricultural Economics/Revue canadienne d'agroeconomie. 2020 Apr.

${ }^{11}$ Ivanov D. Predicting the impacts of epidemic outbreaks on global supply chains: A simulation-based analysis on the coronavirus outbreak (COVID-19/SARS-CoV-2) case. Transportation Research Part E: Logistics and Transportation Review. 2020 Apr 1;136:101922.

${ }^{12}$ Fadel M, Salomon J, Descatha A. Coronavirus outbreak: the role of companies in preparedness and responses. The Lancet Public Health. 2020 Apr 1;5(4):e193.

${ }^{13}$ Cavanagh G, Wambier CG. Rational hand hygiene during the coronavirus 2019 (COVID-19) pandemic. Journal of the American Academy of Dermatology. 2020 Apr 5.

${ }^{14}$ Berger ZD, Evans NG, Phelan AL, Silverman RD. Covid-19: control measures must be equitable and inclusive.

${ }^{15}$ Panigrahi SK, Pathak VK, Kumar MM, Raj U. Covid-19 and mobile phone hygiene in healthcare settings. BMJ Global Health. 2020 Apr 1;5(4):e002505.

${ }^{16}$ Lines WF. ABOUT COVID-19. 
${ }^{17}$ Fathizadeh H, Maroufi P, Momen-Heravi M, Dao S, Köse Ş, Ganbarov K, Pagliano P, Esposito S, Kafil HS. Protection and disinfection policies against SARS-CoV-2 (COVID-19). Infez Med. 2020 Apr;28(2):185-91.

${ }^{18}$ World Health Organization. Rational use of personal protective equipment (PPE) for coronavirus disease (COVID-19): interim guidance, 19 March 2020. World Health Organization; 2020.

${ }^{19}$ Baker MG, Peckham TK, Seixas NS. Estimating the burden of United States workers exposed to infection or disease: a key factor in containing risk of COVID-19 infection. PloS One. 2020 Apr 28;15(4):e0232452.

${ }^{20}$ George R, George A. COVID-19 as an occupational disease?. SAMJ South African Medical Journal. 2020 Apr 1;110(4):NA-.

${ }^{21}$ Belingheri M, Paladino ME, Riva MA. COVID-19: health prevention and control in non-healthcare settings.

${ }^{22}$ Dyal JW. COVID-19 Among Workers in Meat and Poultry Processing Facilities-19 States, April 2020. MMWR. Morbidity and Mortality Weekly Report. 2020;69.

${ }^{23}$ Cook TM. Personal protective equipment during the COVID-19 pandemic-a narrative review. Anaesthesia. 2020 Apr 4. 